\title{
Evaluation of Indoor Air Quality in Different Hospital Wards by Bioaerosol Sampling and Particle Counting in 2016
}

\author{
Ahmad Nikpey ${ }^{1}$, Mohadeseh Choubdar ${ }^{2, *}$, Ali Dastamouz ${ }^{2}$, Mohammad Rahmani ${ }^{3}$ \\ ${ }^{1}$ Associate Professor, Department of Occupational Health, School of Health, Qazvin University of Medical Sciences, Qazvin, \\ Iran \\ ${ }^{2}$ MSc Student, Department of Occupational Health, School of Health, Qazvin University of Medical Sciences, Qazvin, Iran \\ ${ }^{3}$ BSc in Occupational Health, School of Health, Qazvin University of Medical Sciences, Qazvin, Iran
}

* Corresponding Author: Mohadeseh Choubdar, Department of Occupational Health, School of Health, Qazvin University of Medical Sciences, Qazvin, Iran. Email: m.choobdar@gmail.com

Received: 06/12/2017

Accepted: 03/06/2018

How to Cite this Article: Nikpey A, Choubdar M, Dastamouz A, Rahmani M. Evaluation of Indoor Air Quality in Different Hospital Wards by Bioaerosol Sampling and Particle Counting in 2016. J Occup Hyg Eng. 2018; 5(1): 53-60. DOI: 10.21859/ johe-5.1.53

\section{Abstract}

Background and Objective: Hundreds of millions of patients are annually affected by nosocomial infections worldwide, the most important complications of which are mortality and imposition of financial burdens on health systems. The maintenance of adequate indoor air quality (IAQ) at hospitals is critical to the prevention of these infections. The evaluation of IAQ can be performed through bioaerosol sampling and particle counting. Regarding this, the present study aimed to evaluate IAQ by investigating bioaerosol concentration and particle counting in various wards of a hospital in Qazvin province, Iran.

Materials and Methods: This descriptive, analytical, and cross-sectional study was conducted on air samples obtained from seven wards of a hospital in Qazvin. Air samples were taken according to the standards of the National Institute for Occupational Safety and Health using the Andersen impactor equipped with tryptic soy agar and Sabouraud dextrose agar media at a flow rate of $28.3 \mathrm{~L} / \mathrm{min}$ for $10 \mathrm{~min}$. The samples were incubated, then counted in terms of $\mathrm{CFU} / \mathrm{m}^{3}$. The counting of particulate matters was accomplished using China Way CW-HPC200 (A).

Results: The lowest mean fungal and total concentrations were observed in the pathology department and laboratory, while the highest concentration was detected in the Intensive Care Unit and Coronary Intensive Care Unit. The mean $\mathrm{PM}_{2.5}$ and $\mathrm{PM}_{0.3}$ were obtained as $189 \mathrm{n} / \mathrm{m}^{3}$ and $100499 \mathrm{n} / \mathrm{m}^{3}$, respectively. The results of the Spearman test revealed a significant correlation between the total microbial concentration and $\mathrm{PM}_{0.3}(\mathrm{P}=0.003)$.

Conclusion: As the findings indicated, bioaerosol concentration was higher in the hospital than in outdoor. This might be related to the presence of patients, their activities, as well as unsuitable ventilation and disinfection. Therefore, continuous monitoring, enhancement of hygienic disinfection standards, and promotion of ventilation systems are needed to improve IAQ, especially in the hospital wards.

Keywords: Bioaerosol, Hospitals; IAQ; Particulate Matter 
dof: 10.21859 /johe- 5.1 .53

\title{
ارزيابى كيفيت هوا در بخشهاى مختلف بيمارستانى با تأكيد بر نمونهبردارى از بيو آئروسلها و شمارش ذرات
}

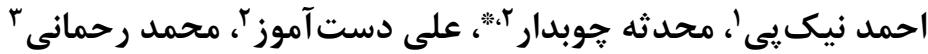

' ' دانشيار، گروه مهندسى بهداشت حرفهاى، دانشكده بهداشت، دانشعاه علوم يزشكى قزوين، قزوين، ايران

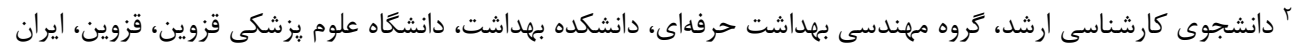

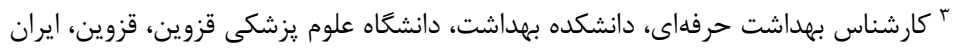

* نويسنده مسئول: محدثه جوبدار، گروه مهندسى بهداشت حرفهاى، دانشكده بهداشت، دانشگاه علوم يزشكى قزوين، قزوين، ايران. ايميل:m.choobdar@gmail.com

جكيده

سابقه و هدف: ساليانه صدها ميليون بيمار در جهان از عفونتهاى بيمارستانى رنج مىبرند كه برجستهترين

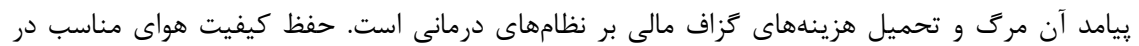

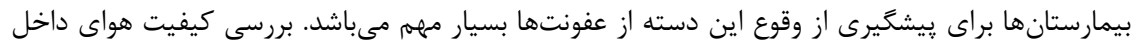

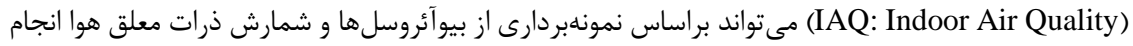

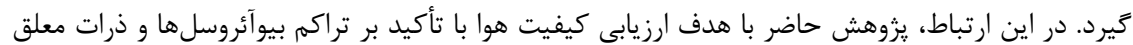

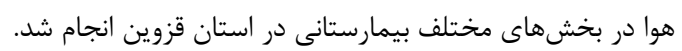

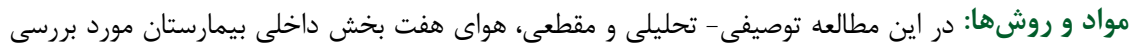

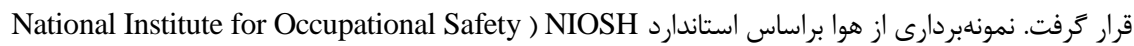

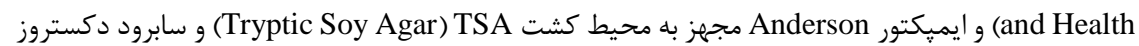

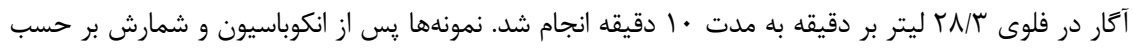

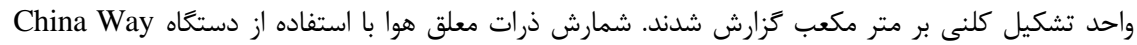

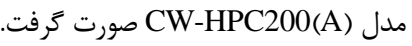

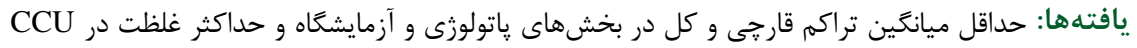

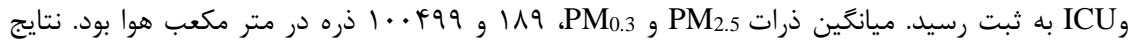

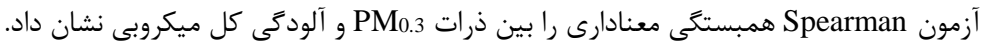

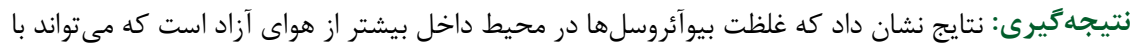

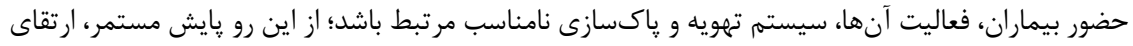

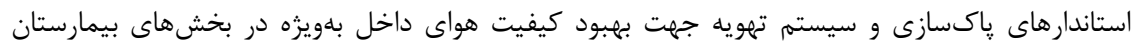
ويشنهاد مى گردد.

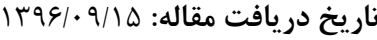

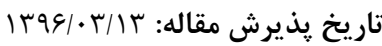
تمامى حقوق نشر براى دانشكاه علوم يزشكى همدان محفوظ است.

وازگًان كليدى: بيمارستانها؛ بيوآئروسلها؛ ذرات معلق هوا؛ IAQ

براى شاغلين، بيماران و حتى عيادت كنندگان به شمار مىروند

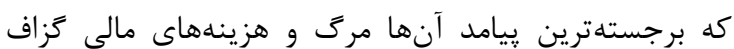
مىباشد. شيوع اين عفونتها در كشورهاى درحال توسعه و

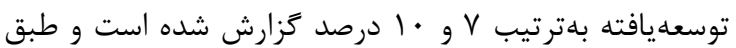

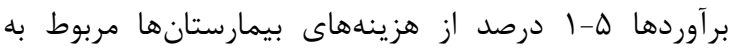

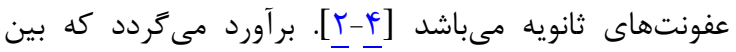

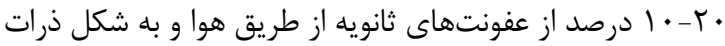

مقلدمه كيفيت هواى داخل از شاخصهاى اصلى سلامت محيطهاى

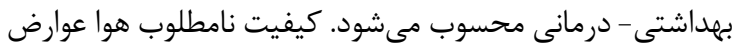

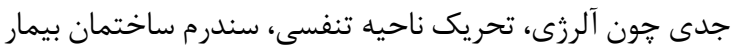

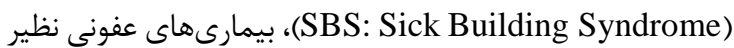

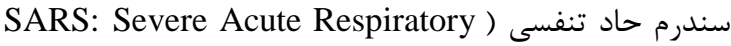

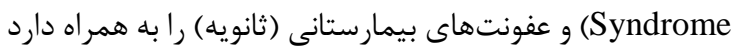
[1]]. عفونتهاى بيمارستانى يكى از مهممترين عوامل مخاطرهآميز 
بيمارستان واقع در شهر قزوين براساس شمارش ذرات هوابرد و

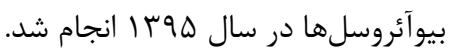

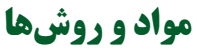

اين مطالعه توصيفى- تحليلى با روش مقطعى در زمستان

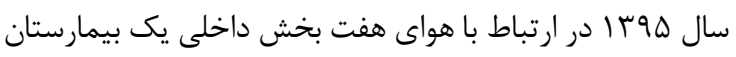
شامل: مراقبتهاى ويزه (ICU: Intensive Care Unit)، اتاق هراق

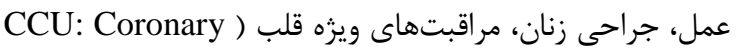

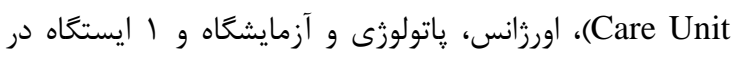

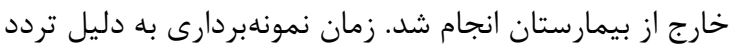

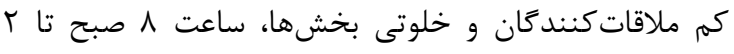

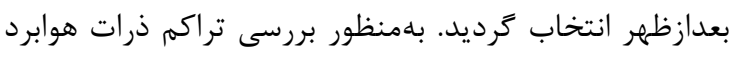

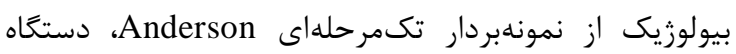
ساخت كشور انخلستان و روش استاندارد

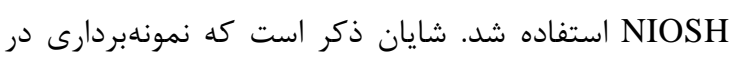

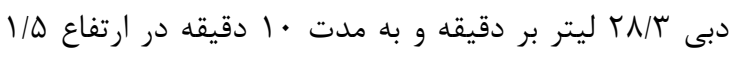

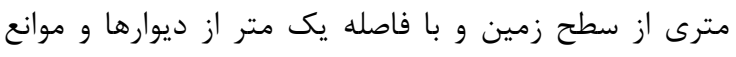

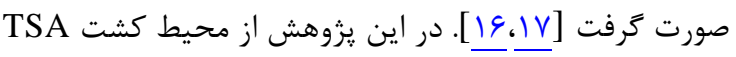

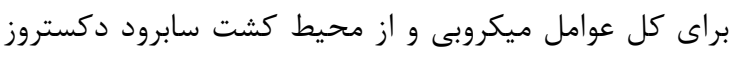

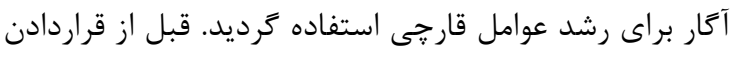

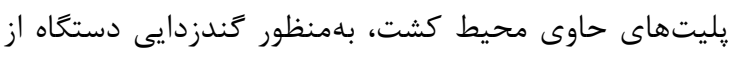

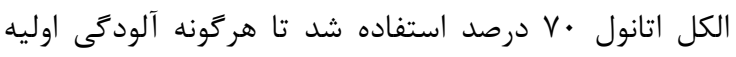

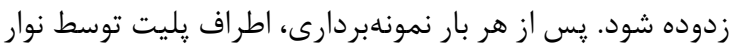

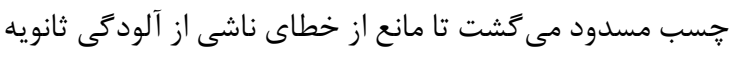

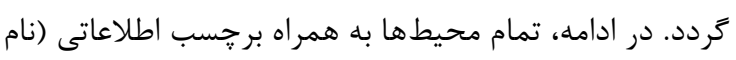

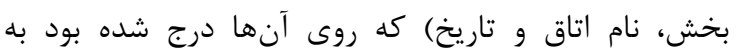

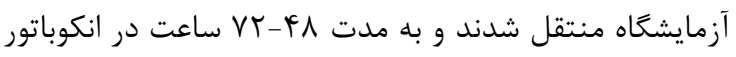

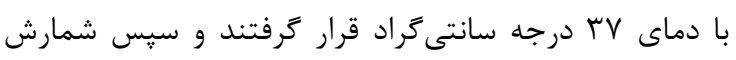

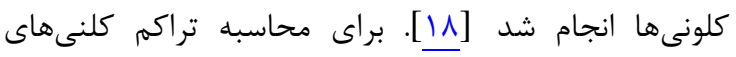

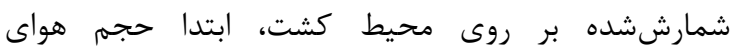

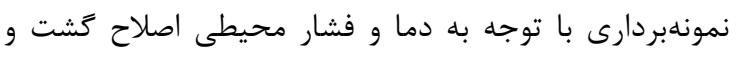

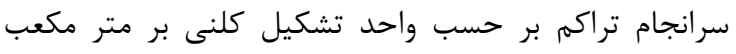

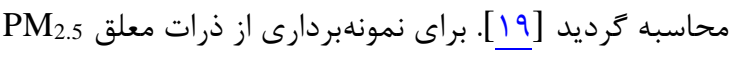

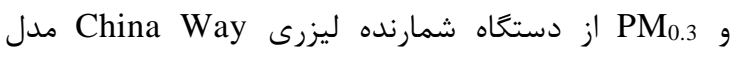
CW-HPC200(A)

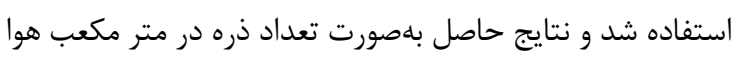
كزارش گرديد. سنجش دما و رطوبت نسبى نيز نيز توسط دستخاه

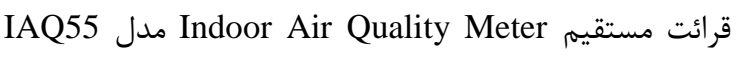

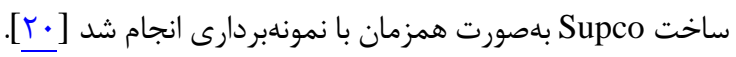

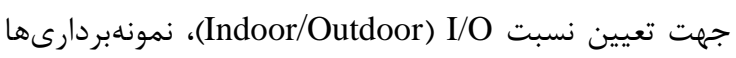

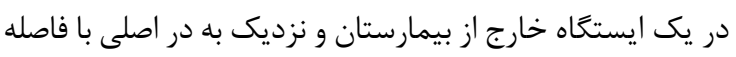

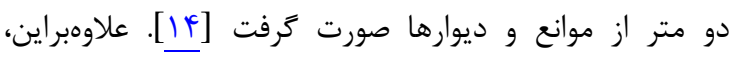

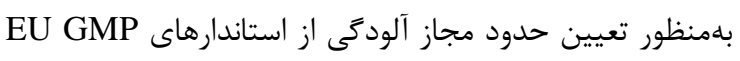
و (EuropeanUnion Good Manufacturing Practice)
معلق منتقل مىشوند. انتقال هوابرد به عفونتهاى ناشى از

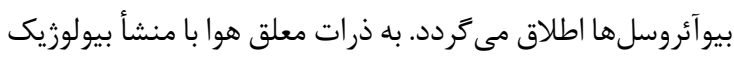

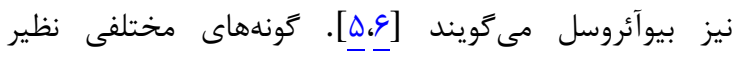

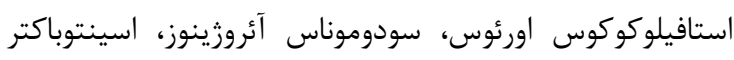

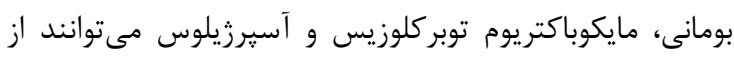

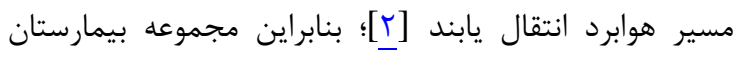

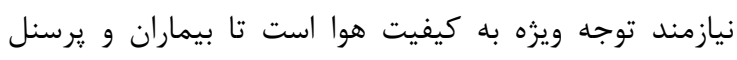

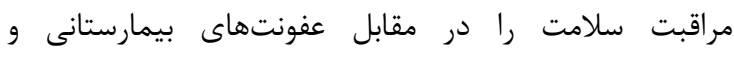

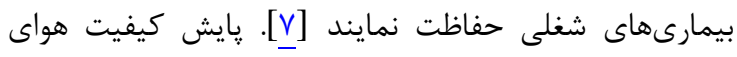

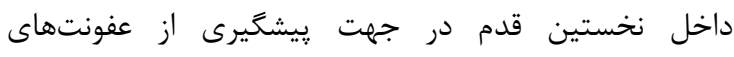

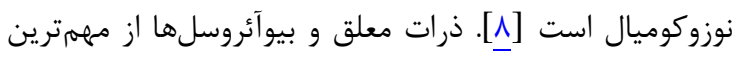

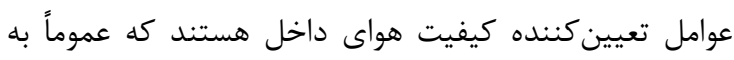

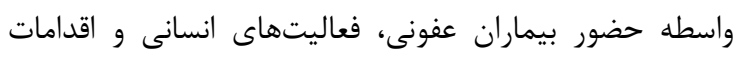

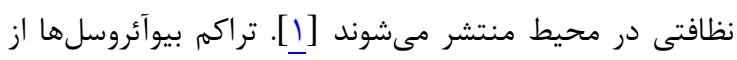

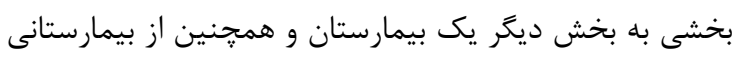

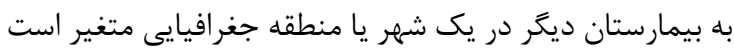

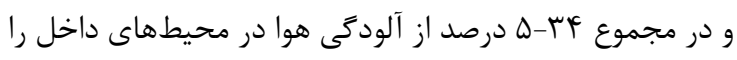

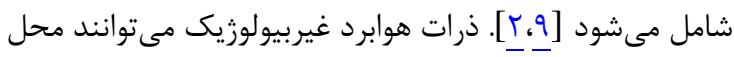

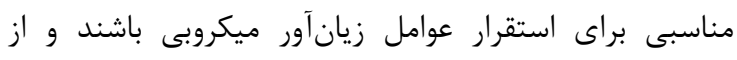

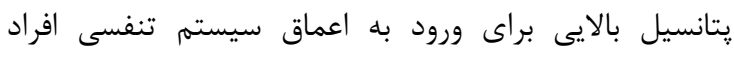

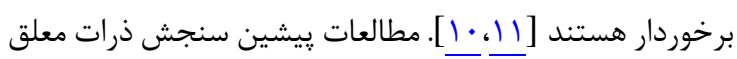

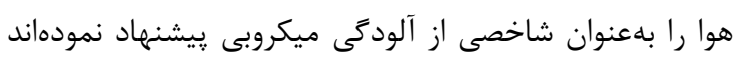

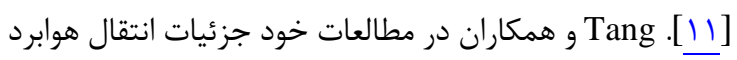

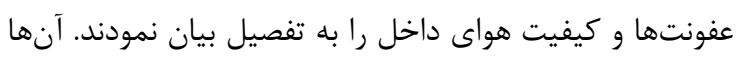

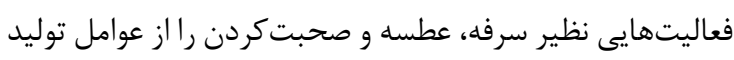

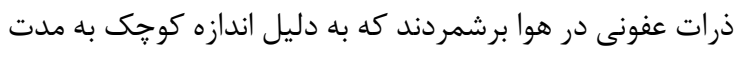

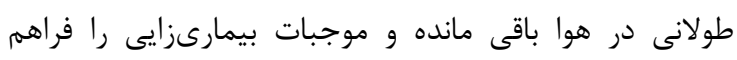

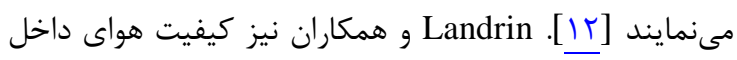

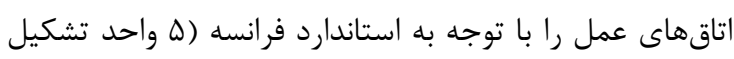

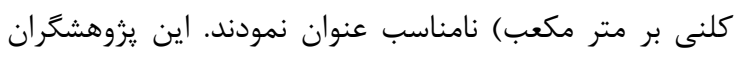

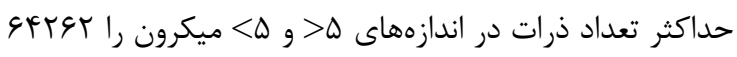

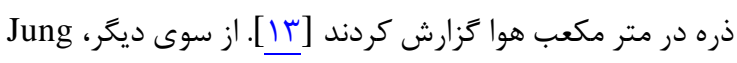

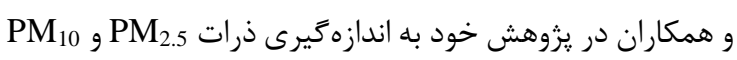
و كازهايى جون

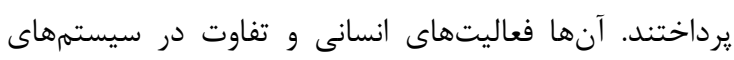

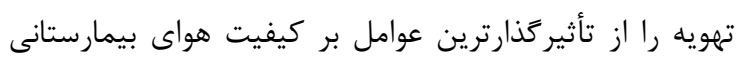

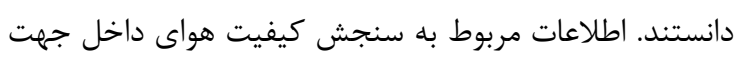

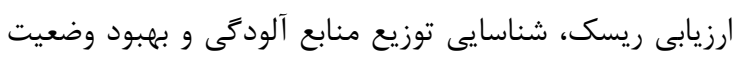

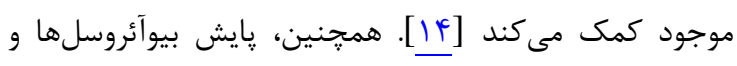

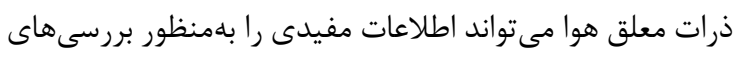

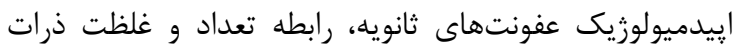

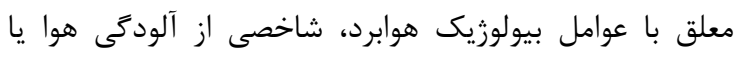

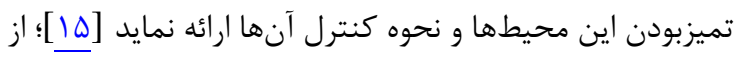

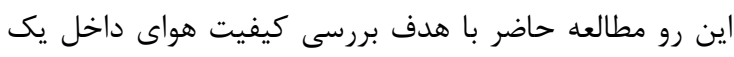


معلق PM0.3 از استاندارد ISO كلاس 9 استفاده شد كه در آن

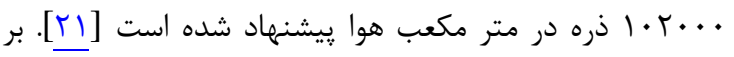

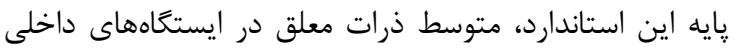
يايينتر از حد توصيه شده بود.

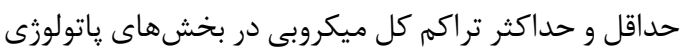

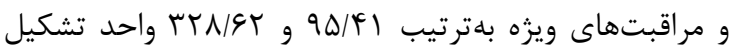

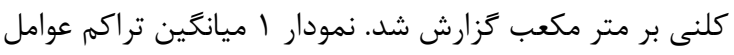

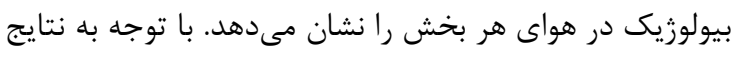

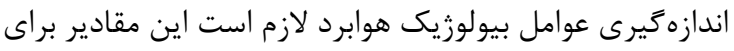

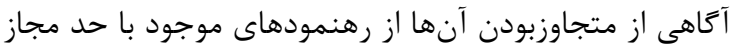

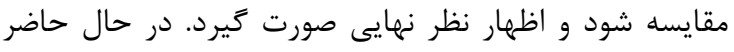

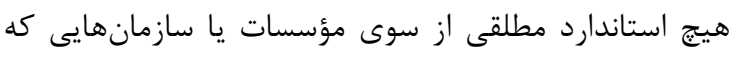

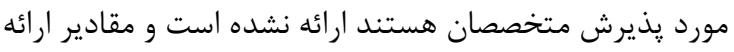

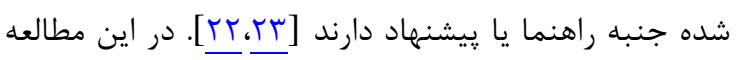

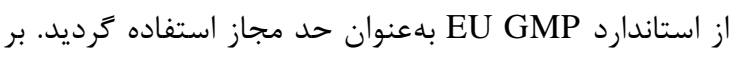

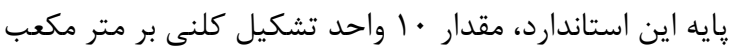

كلاس 9 استفاده گرديد. تجزيه و تحليل دادهها با استفاده

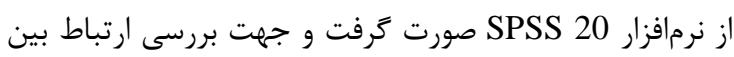

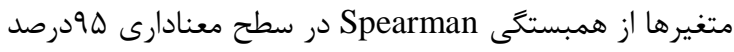
استفاده شد.

كافتهنها

براساس نتايج حاصل از نمونهَيرىها مشخص گرديد كه

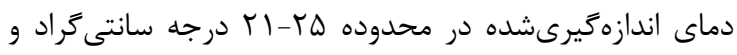

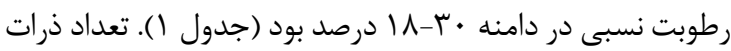

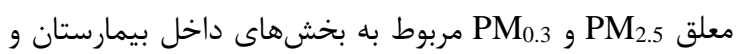
هواى محوطه بيرون در جدول ا ارائه شده است. مطابق با نتايج اين جدول، بيشترين تعداد ذرات PM و PM

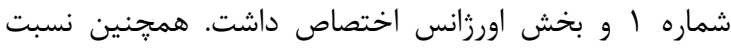

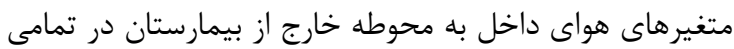

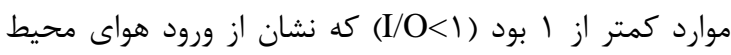
بيرونى به محيط داخلى دارد. بلمنظور تعيين سطح مجاز ذرات

\begin{tabular}{|c|c|c|c|c|}
\hline \multicolumn{4}{|c|}{ متغير } & \multirow[b]{2}{*}{ 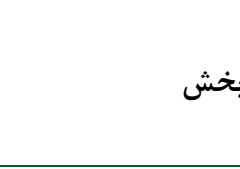 } \\
\hline رطوبت نسبى (درصد) & دما (سلسيوس) & 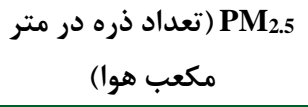 & $\begin{array}{c}\text { مكعب هوا) (تعداد ذره در متر PM0.3 } \\
\text { مكراد }\end{array}$ & \\
\hline TV/A & $r \mid / r$ & rI. & $|f q| \ldots$ & اورزانس \\
\hline TQ & TF & 191 & IfTF.. & آزمايشگاه \\
\hline tr & $r M / D$ & IfV & IrgVqF & ياتولوزى \\
\hline r & $r / / D$ & TAT & $\Delta q \cdot V r$ & اتاق عمل شماره | \\
\hline$r N / Q$ & $r T / V$ & $1 \cdot 0$ & $\Delta V \wedge r F$ & اتاق عمل شماره r \\
\hline 11 & $r \Delta / 1$ & rI. & $\Lambda \cdot \wedge \vee 1$ & $\mathrm{CCU}$ \\
\hline rq & $r T / \Delta$ & $1 \cdot \Delta$ & DAGTr & ICU \\
\hline$r \cdot$ & rI & ma & AVGit & جراحى زنان \\
\hline$r \Delta / \varphi \& \pm r / \Lambda$ & $r r / \Delta V \pm 1 / \Delta$ & । $৭ \pm V r / V$ & $1 \cdots+q 99 \pm r q 199 / 8$ & انحراف معيار دميانكين \\
\hline$\Delta 1$ & $9 / 1$ & Trr & $I T \cdot V T \Delta$ & هواى آزاد \\
\hline$\cdot 10$ & $T / \mu$ & $\cdot / V$ & $\cdot / \Lambda$ & ل نسبت I/O \\
\hline
\end{tabular}

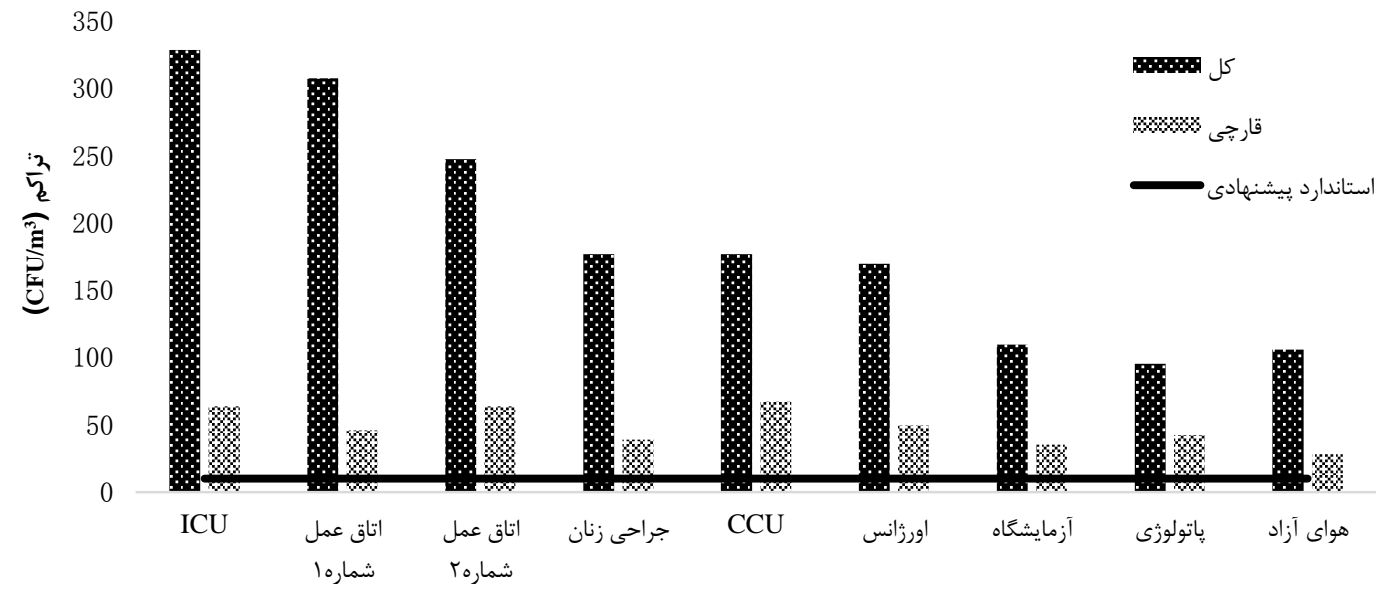


بهمنظور ارزيابى ارتباط متغيرهاى مورد بررسى با يكديخر از

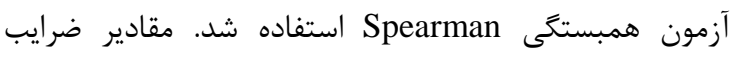
همبستگى در جدول r T ارائه شده است. نتايج حاصل تنها

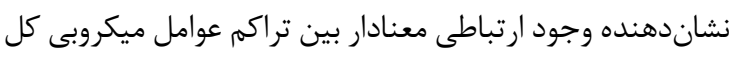

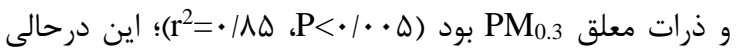

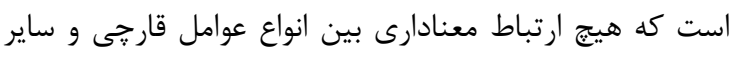

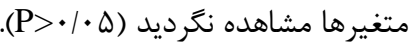

نشاندهنده محيط تميز است؛ بنابراين آلودگى كليه بخشها

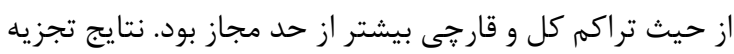

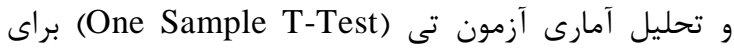

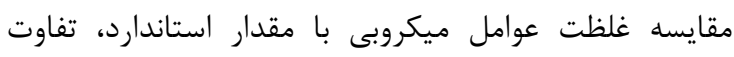

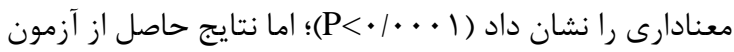
Kruskal-Wallis ميكروبى بخش هاى بيمارستان نشان نداد (Q) • (P=).

جدول r: بررسى ارتباط ذرات معلق هوا و بيوآئروسل ها در بخشهاى داخلى بيمارستان و هواى آزاد

\begin{tabular}{|c|c|c|c|c|}
\hline \multicolumn{2}{|c|}{ تراكم بيو آئروسلهاى كل } & \multicolumn{2}{|c|}{ تراكم بيو آئروسل هاى قارجى } & \multirow{2}{*}{ متغير } \\
\hline Coefficient Spaerman & Sig. & Coefficient Spaerman & Sig. & \\
\hline. $\mid 94$ & $\cdot / \cdot V$ & - & - & تراكم بيوآئروسل هاى قارجى \\
\hline- & - & $\cdot 194$ & $\cdot / \cdot V$ & تراكم بيوآئروسلهاى كل \\
\hline$\cdot|r|$ & .109 & $\cdot|0|$ & .119 & $\mathrm{PM}_{2.5}$ \\
\hline$\cdot / \Lambda \Delta$ & $\cdot / \cdot r$ & $\cdot 194$ & .1 .9 & $\mathrm{PM}_{0.3}$ \\
\hline
\end{tabular}

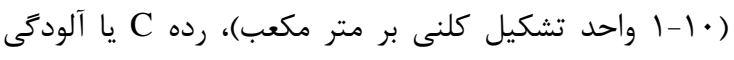

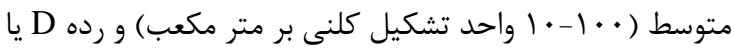

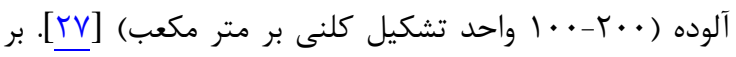

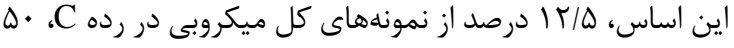

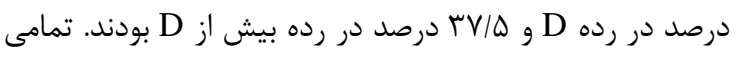
نمونههاى قارجى نيز در رده D قرار داشتند. از سوى ديخر، در درد

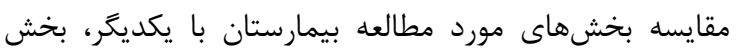
ياتولوزى به دليل تردد كم افراد و داشتن يك فرد شاغل كمترين

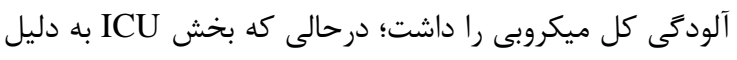

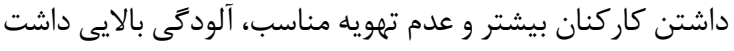

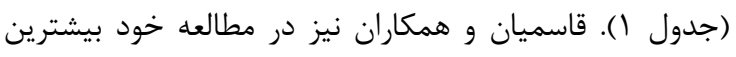

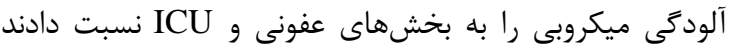

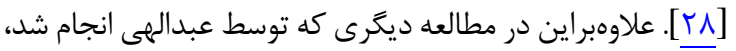

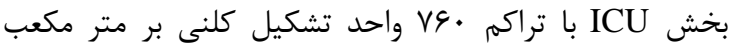

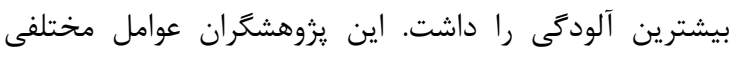
همجون روش نامناسب استريليزاسيون، سيستم نامناسب تهويه

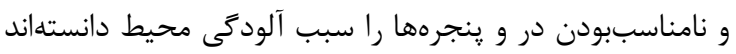

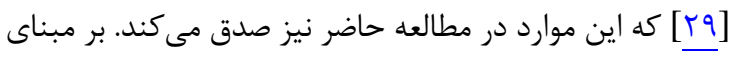

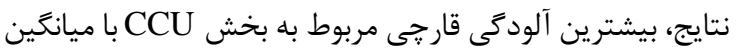

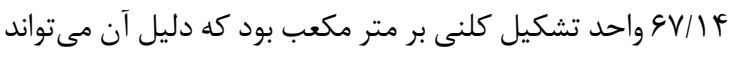

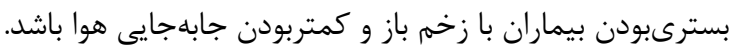

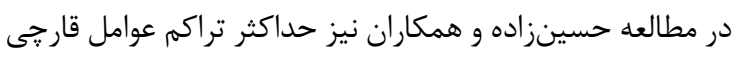

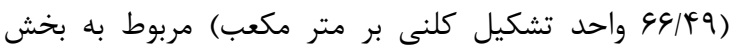

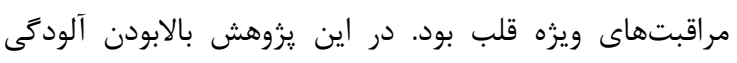

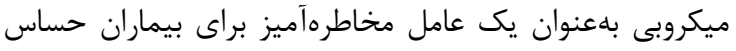

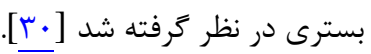

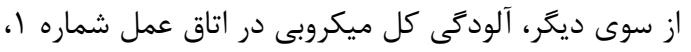

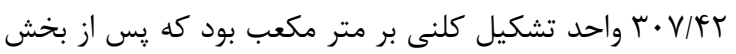

بر مبناى نتايج يزوهش حاضر ميانگين درجه حرارت و

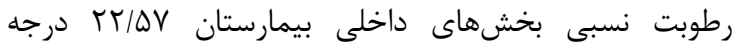

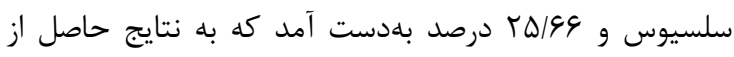

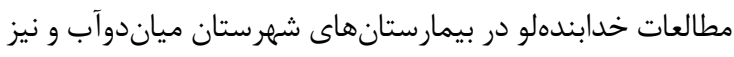
يزوهش شاركوى در ارتباط با بررسى بيمارستانهاى آموزشى دئن

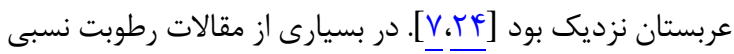

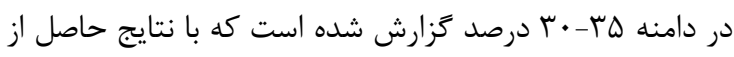

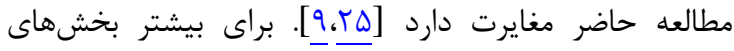

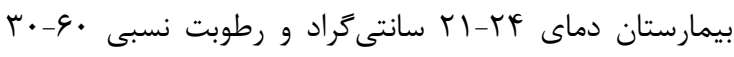

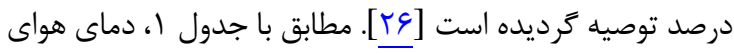

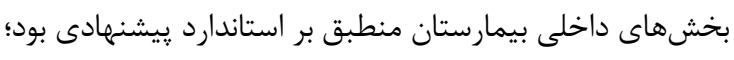

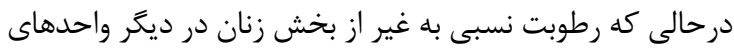

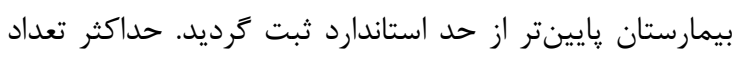

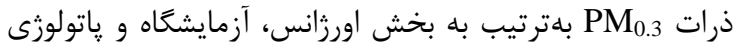

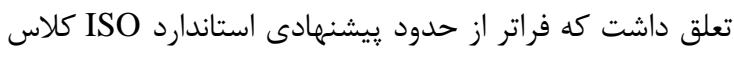
9 بود. در بخش اورزانس به دليل تردد بالاى مراجعه كنند

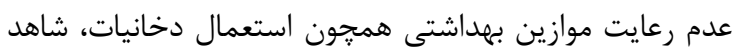

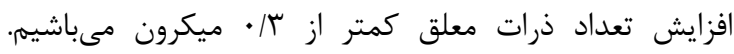

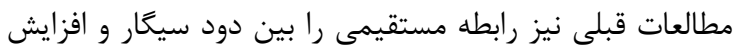

ذرات PM با وجود اينكه خطرات بهداشتى مواجهه با بيوآئروسلها

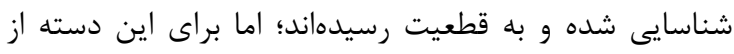

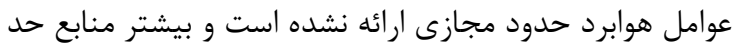

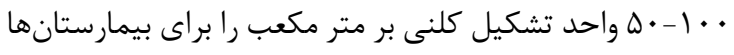

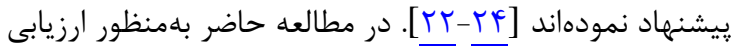

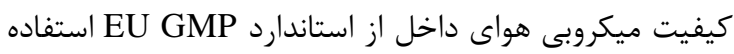

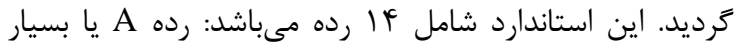
تميز (1> واحد تشكيل كلنى بر متر مكعب)، رده B يا تميز 
داخل و بيرون وجود داشت [IV]؛ به همين دليل يارامترهاى

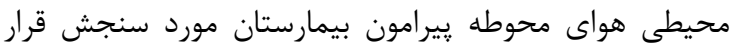

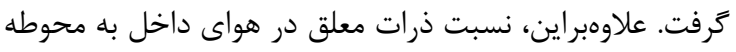

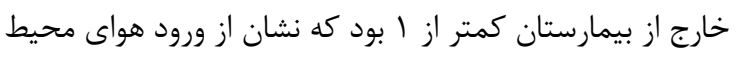

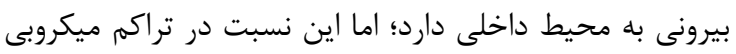

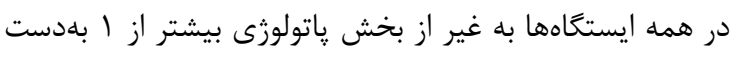

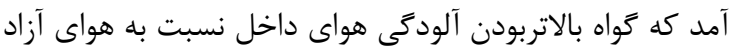

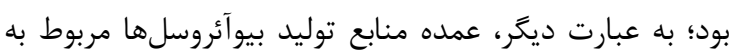
بخشهاى داخلى بود. در يزوهش حاضر علاوه بر مقايسه آلودى بـى با مقادير

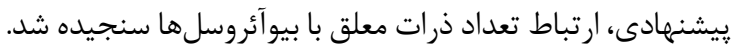

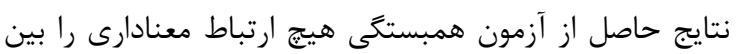

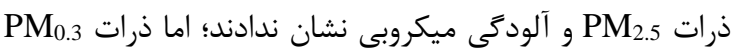

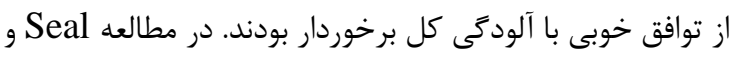
عامل Clark

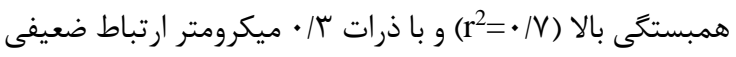

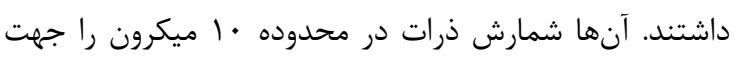

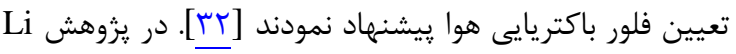

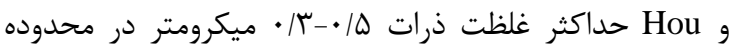

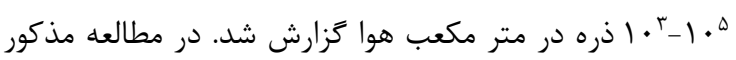

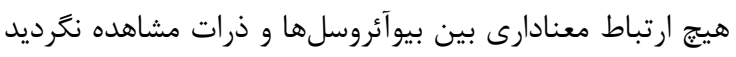

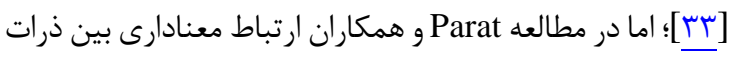

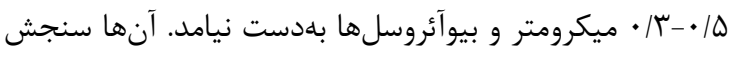

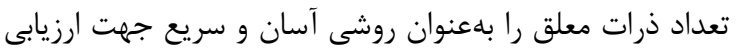

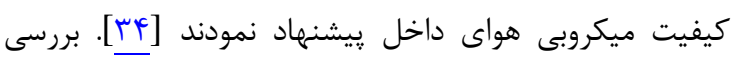

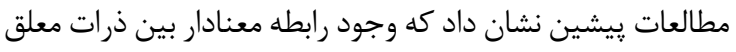

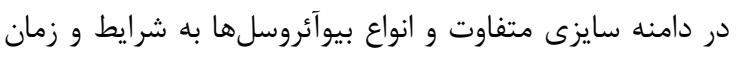

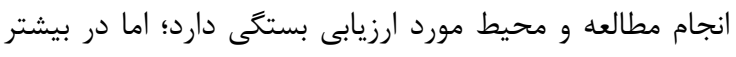

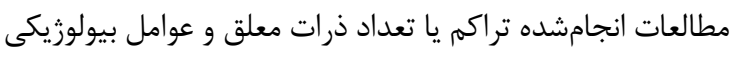

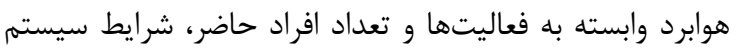

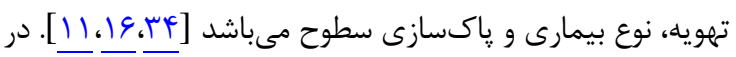

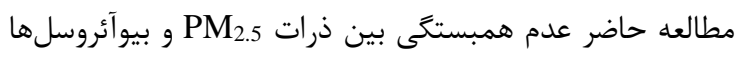

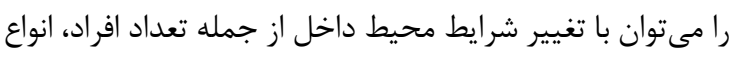

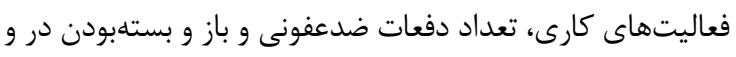

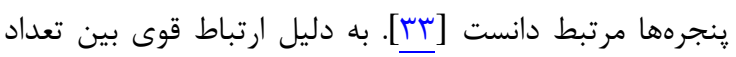

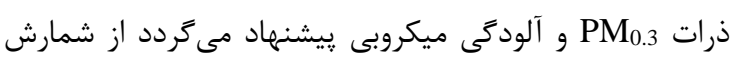

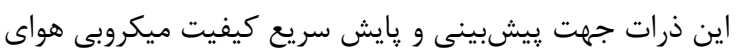

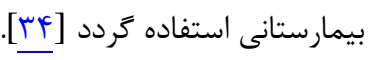

\section{نتيجه كيرى}

در مطالعه حاضر بهمنظور بررسى كيفيت هواى داخل بيمارستان از شمارش ذرات معلق PM د

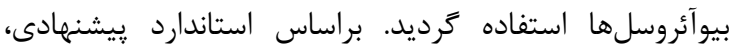

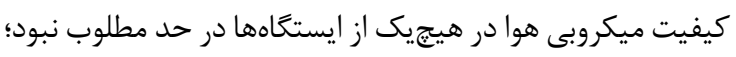

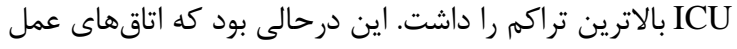

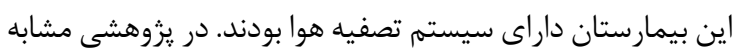

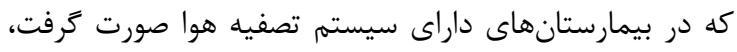

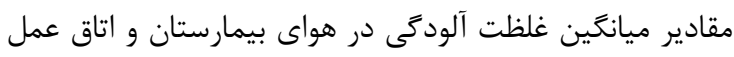

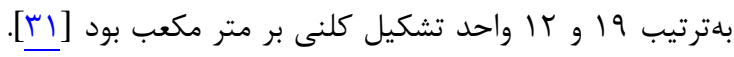

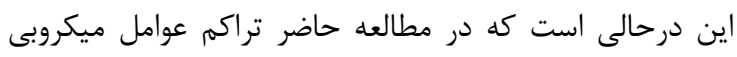

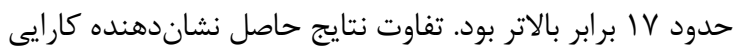

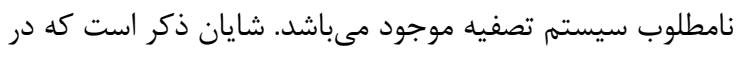

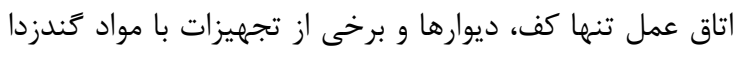

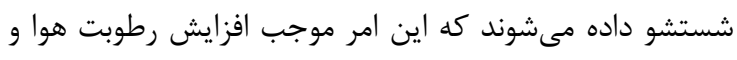

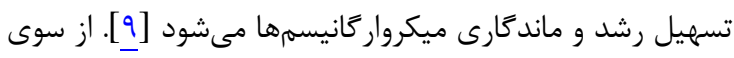

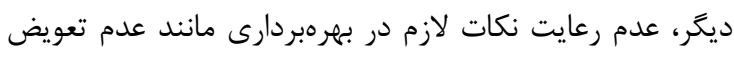

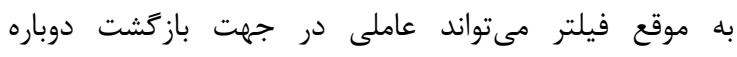

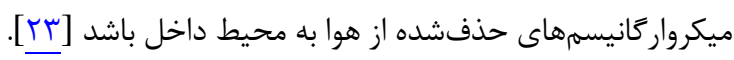
در يزوهش جوبينه و همكاران [IV]

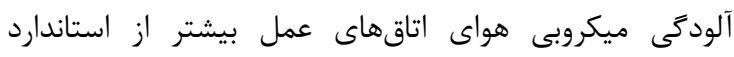

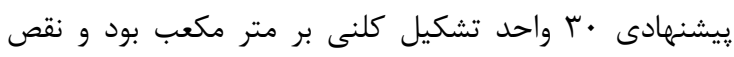

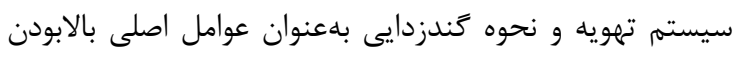

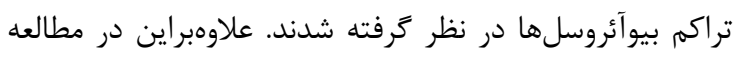
Scaltriti

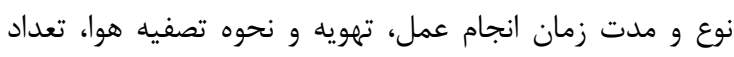

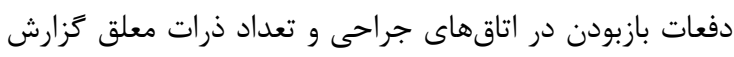

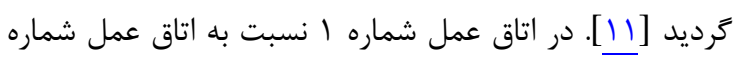

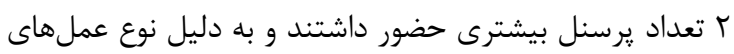

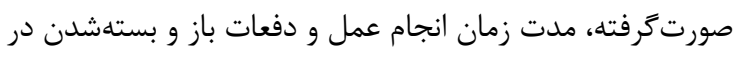

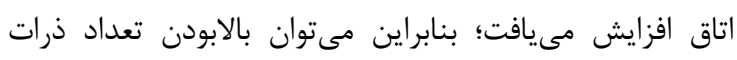

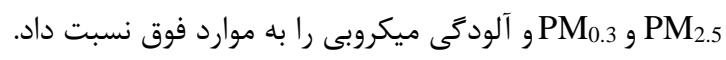

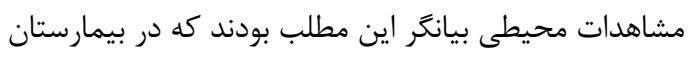

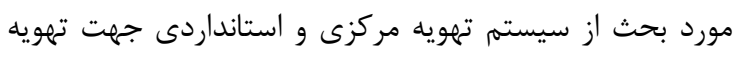

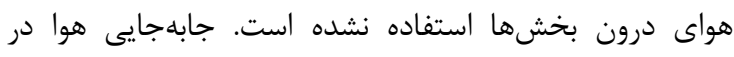

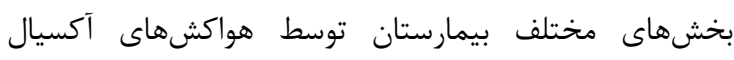

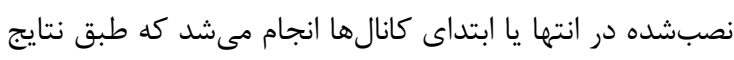

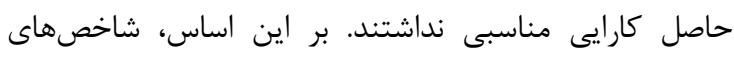

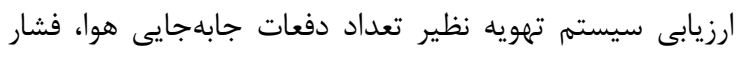

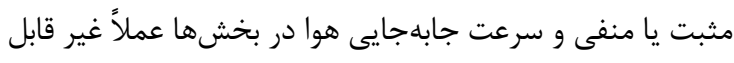

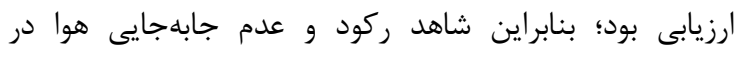

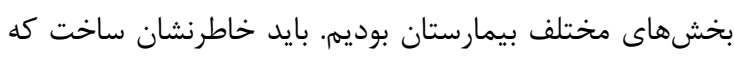

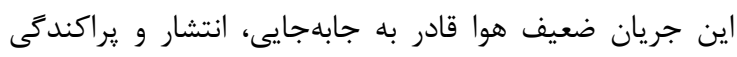

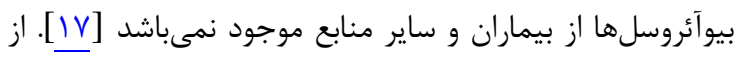

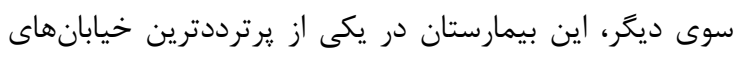

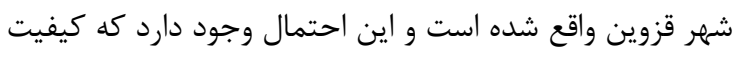

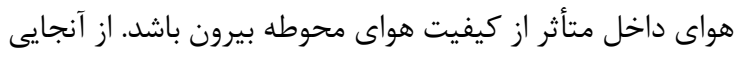

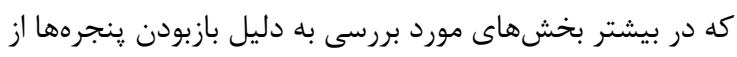

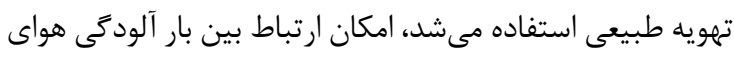




$$
\begin{aligned}
& \text { ورود جريان هواى خارج به داخل اتاقها (به غير از اتاق ايزوله } \\
& \text { [rr] تنفسى و برونكوسكويى) } \\
& \text { - - استفاده از هواى تميز تكجهتى درونى در برخى از واحدها نظير }
\end{aligned}
$$

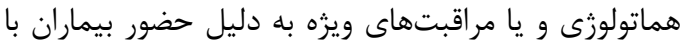

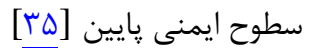

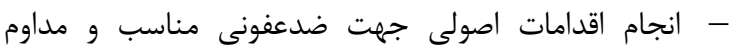

$$
\begin{aligned}
& \text { بخشها تحت نظر متخصصان اين امر } \\
& \text { تشكر و قرر فاذى } \\
& \text { نويسندكان مقاله مراتب تشكر و قدردانى خود را از مسئولين }
\end{aligned}
$$

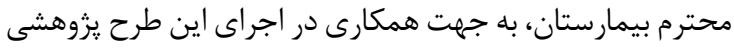

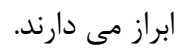

\section{REFERENCES}

1. Yau YH, Chandrasegaran D, Badarudin A. The ventilation of multiple-bed hospital wards in the tropics: a review. Build Environ. 2011;46(5):1125-32. DOI: 10.1016/j.buildenv. 2010.11.013

2. King MF, Noakes CJ, Sleigh PA, Camargo-Valero MA. Bioaerosol deposition in single and two-bedhospital rooms: anumerical and experimental study. Build Environ. 2013;59:436-47. DOI: 10.1016/j.buildenv.2012.09.011

3. Chen YY, Chou YC, Chou P. Impact of nosocomial infection on cost of illness and length of stay in intensive care units. Infect Control Hosp Epidemiol. 2005;26(3):281-7. PMID: 15796281DOI: $10.1086 / 502540$

4. Maesoumy Asil H, Zahraee M, Majidpour A, Nateghian A, Afhamy S, Rahbar M, et al. Country guide for the hospital care system. Tehran: Center for Disease Management, in Collaboration with the Chakameava; 2006. [Persian]

5. Fletcher LA, Noakes CJ, Beggs CB, Sleigh PA. The importance of bioaerosols in hospital infections and the potential for control using germicidal ultraviolet irradiation. Proceedings of the First Seminar on Applied Aerobiology, Murcia, Spain; 2004.

6. Rathore L, Khatri PK, Chandora A, Meena S, Bora A, Maurya V, et al. Microbial profile and antibiogram of air contamination in hospital wards of a tertiary care hospital, western Rajasthan, India. Int J Curr Microbiol Appl Sci. 2015;4(8):40-6.

7. El-Sharkawy MF, NoweirME. Indoor air quality levels in a University Hospital in the Eastern Province of Saudi Arabia. J Family Community Med. 2014;21(1):39-47. PMID: 24696632 DOI: $10.4103 / 2230-8229.128778$

8. Okten S, Asan A. Airborne fungi and bacteria in indoor and outdoor environment of the Pediatric Unit of Edirne Government Hospital. Environ Monit Assess. 2012;184(3):1739-51. PMID: 21611848 DOI: 10.1007/s10661011-2075-X

9. Hoseinzadeh E, Samarghandie MR, Ghiasian SA, Alikhani MY, Roshanaie G, Moghadam Shakib M. Qualitative and quantitative evaluation of bioaerosoles in the air of different wardsof governmental Hamedan hospitals, during 20112012. Yafteh. 2012;14(4):29-39.

10. Alghamdi MA, Shamy M, Redal MA, Khoder M, Awad AH, Elserougy S. Microorganisms associated particulate matter: a preliminary study. Sci Total Environ. 2014;479:109-16. PMID: 24561289 DOI: 10.1016/j.scitotenv.2014.02.006

11. Scaltriti S, Cencetti S, Rovesti S, Marchesi I, Bargellini A, Borella P. Risk factors for particulate and microbial contamination of air in operating theatres. J Hosp Infect. 2007;66(4):320-6. PMID: 17655973 DOI: 10.1016/j.jhin. 2007.05.019

12. Tang JW, Li Y, Eames I, Chan P, Ridgway GL. Factors involved in the aerosol transmission of infection and control of ventilation in healthcare premises. J Hosp Infect.

$$
\begin{aligned}
& \text { اما متوسط تعداد ذرات معلق پايينتر از استاندارد ISO كلاس } 9 \\
& \text { بود. توصيه مى گردد در مطالعات آتى عوامل باكتريايى، شناسايى } \\
& \text { گَونههاى ميكروبى و بررسى دقيق يارامترهاى مؤثر بر كارايى } \\
& \text { سيستمهاى تهويه مورد ارزيابى قرار گيرند. } \\
& \text { بيشنمادات } \\
& \text { در مجموع، جهت بهبود وضعيت موجود موارد زير زيشنهاد } \\
& \text { مى كردد: } \\
& \text { - - انجام نمونهبردارى مستمر از ذرات براى تأييد كارايى سيستم } \\
& \text { تهويه موجود } \\
& \text { - } \\
& \text { كيفيت ميكروبى هوا } \\
& \text { - - اعمال فشار مثبت در داخل اتاق/ بخش جهت جلوخيرى از }
\end{aligned}
$$

2006;64(2):100-14. PMID: 16916564 DOI: 10.1016/j.jhin. 2006.05.022

13. Landrin A, Bissery A, Kac G. Monitoring air sampling in operating theatres: can particle counting replace microbiological sampling? J Hosp Infect. 2005;61(1):27-9. PMID: 16009457 DOI: 10.1016/j.jhin.2005.03.002

14. Jung $\mathrm{CC}, \mathrm{Wu} \mathrm{PC}$, Tseng $\mathrm{CH}$, Su HJ. Indoor air quality varies with ventilation types and working areas in hospitals. Build Environ. 2015;85(5):190-5.DOI: 10.1016/i.buildenv. 2014.11.026

15. Rostami N, Alidadi H, Zarrinfar H, Salehi P. Assessment of indoor and outdoor airborne fungi in an Educational, Research and Treatment Center. Italian J Med. 2016; 11(1):52-6. DOI: 10.4081/itjm.2016.663

16. Sepahvand A, Godini H, Omidi Y, Tarrahi M, Rashidi R, Basiri $\mathrm{H}$. Investigation of fungal bioaerosols and particulate matter in the teaching-medical hospitals of Khorramabad City, Iran during 2015. Iran J Health Environ. 2016;9(1):115-26. [Persian]

17. Choobineh A, Rostam R, Tabatabaei SH. Assessment of bioaerosolstypes and concentration inambientairof Shiraz University of Medical Sciences Educational Hospitals, 2008. Iran Occupat Health. 2009;6(2):69-76. [Persian]

18. Kowalski W. Hospital airborne infection control. Florida: CRC Press; 2012.

19. Malakootian M, Gharghani MA. Investigation of type and density of bio-aerosols in air samples from educational hospital wards of Kerman city, 2014. Environ Health Engine Manage J. 2016;3(4):197-202. DOI: 10.15171/EHEM. 2016.20

20. Yassin MF, Almouqatea S. Assessment of airborne bacteria and fungi in an indoor and outdoor environment. Int $J$ Environ Sci Technol. 2010;7(3):535-44.

21. Universal T, Universal T, Standard F. FS209E and ISO cleanroom standards. Fullerton: Terra Universal Inc; 2012.

22. Massoudinejad M, Niknahad E. Determination of the amount of bioaerosols in hospital environments.J Saf Promot Injury Prev. 2014;1(4):198-204. [Persian]

23. A Guide To Ventilation System In Hospital.Center Iroimohameeaoh. Tehran: Tehran University of Medical Sciences; 2014. [Persian]

24. Khodabandelou H, Rasoulzadeh Y, Mirzaeei R, Rezaeei MA. Bio-aerosols variety and concentration in different hospital wards of Miandoab City in winter. Med J Tabriz Univ Med Sci Health Ser. 2016;38(3):58-65. [Persian]

25. Dehdashti A, Sahranavard N, Rostami R, Barkhordari A Banayi Z. Survey of bioaerosols type and concentration in the ambient air of hospitals in Damghan, Iran. Occupat Med Quart J. 2013;4(3):41-51. [Persian]

26. Sehulster L, Chinn RY, Arduino M, Carpenter J, Donlan R, Ashford D, et al. Guidelines for environmental infection control in health-care facilities. Morbid Mortal Week Rep 
Recommend Rep RR. 2003;52(10):1-66.

27. Pasquarella C, Pitzurra O, Savino A. The index of microbial air contamination. $J$ Hosp Infect. 2000;46(4):241-56. PMID: 11170755 DOI: $10.1053 /$ /hin.2000.0820

28. Ghasemian A, Khodaparast S, Moghadam FS, Nojoomi F, Vardanjani HR. Types and levels of bioaerosols in healthcare and community indoor settings in Iran. Avicenna J ClinMicrobiolInfect. 2016;4(1):e41036. DOI: 10.17795/ ajcmi-41036

29. Abdolahi AR, Mehrazma M. Concurrence of nosocomial infections with microorganisms spreading in the air of hospital wards. Med Lab J. 2009;3(2):40-5. [Persian]

30. Hoseinzadeh E, Taghavi M, Samarghandie MR. Evaluation of fungal and bacterial aerosols in the different wards of Malayer city's hospitals in 2011-2012. J Hosp. 2014;13(3):99-108. [Persian]

31. Azizifar M, Jabbari H, Naddafi K, Nabizadeh, Tabaraie Y, Solgi A. A qualitative and quantitative survey on air- transmitted fungal contamination in different wards of Kamkar Hospital in Qom, Iran, in 2007. Qom Univ Med Sci J. 2009;3(3):25-30.[Persian]

32. Seal DV, Clark RP. Electronic particle counting for evaluating the quality of air in operating theatres: a potential basis for standards? J Appl Microbiol. 1990;68(3):225-30. PMID: 2341326

33. Li CS, Hou PA. Bioaerosol characteristics in hospital clean rooms. SciTotal Environ. 2003;305(1):169-76. PMID: 12670766 DOI: 10.1016/S0048-9697(02)00500-4

34. Parat S, Perdrix A, Mann S, Baconnier P. Contribution of particle counting in assessment of exposure to airborne microorganisms. Atmos Environ. 1999;33(6):951-9. DOI: 10.1016/S1352-2310(98)00218-0

35. Environmental health guideline for limitedand outpatient surgical centers Islamic Republic Of Iran.Tehran: Ministry of Health and Medical Education Enviromental and Occupational Health Center; 2012. [Persian] 